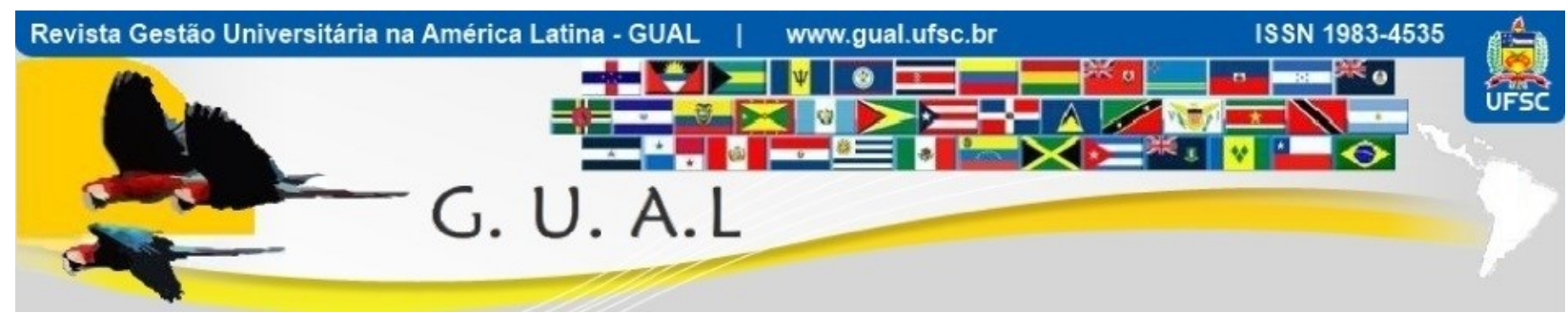

DOI: http://dx.doi.org/10.5007/1983-4535.2018v11n3p281

\title{
IMAGEM INSTITUCIONAL: AVALIAÇÃO DA UNIVERSIDADE FEDERAL DA INTEGRAÇÃO LATINO- AMERICANA (UNILA) SEGUNDO O PÚBLICO INTERNO E EXTERNO
}

INSTITUTIONAL IMAGE: EVALUATION OF THE UNIVERSIDADE FEDERAL DA INTEGRAÇÃO LATINO-AMERICANA (UNILA), ACCORDING TO THE INTERNAL AND EXTERNAL PUBLIC

Fernanda Sotello, Mestre Universidade Federal da Integração Latino-Americana - UNILA fernandasotello@gmail.com

Eduardo Hack Neto, Doutor Universidade Estadual do Oeste do Paraná - UNIOESTE professoreduardohack@gmail.com

Elói Junior Damke, Doutor Universidade Estadual do Oeste do Paraná - UNIOESTE eloi.damke@gmail.com

Recebido em 01/maio/2017

Aprovado em 05/agosto/2018

Sistema de Avaliação: Double Blind Review

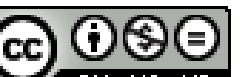

Esta obra está sob uma Licença Creative Commons Atribuição-Uso. 


\title{
RESUMO
}

Um número crescente de estudos tem buscado avaliar a imagem institucional nos diferentes segmentos organizacionais. Todavia, ainda são poucos aqueles que associam os fatores e atributos do modelo de Barich e Kotler (1991) como determinantes na formação da imagem em Instituições de Ensino Superior (IES). Assim, tendo como base o aporte teórico desses autores, o objetivo desse estudo foi analisar a imagem da Universidade Federal da Integração Latino-Americana - UNILA, segundo o público interno (gestores, técnicos, docentes e alunos) e externo (moradores de Foz do Iguaçu). O método com delineamento descritivo e quantitativo, foi aplicado, mediante questionário, em 207 pessoas do público interno, e 269 do externo. Como resultado, constatou-se que a imagem geral da universidade em fatores como Conduta Institucional; Conduta Social; Conduta com Servidores; Atividades de Suporte; Infraestrutura; Produtos e Serviços; Preço; e, Comunicação, situa-se como regular (internamente) e ruim (externamente). Para melhoria dessa imagem, foram sugeridas ações como implantação de um comitê de comunicação e cascateamento de informações na IES, monitoramento das notícias divulgadas na mídia sobre a UNILA, utilização de canais mais próximos à comunidade externa (jornais, rádio, mídias sociais, etc.), e pesquisas periódicas para avaliar a imagem da universidade segundo o público interno e externo.

Palavras chave: Imagem. Dimensões. UNILA. Foz do Iguaçu.

\begin{abstract}
A growing number of studies have sought to evaluate the institutional image in different organizational segments. However, there are still few who associate the factors and attributes of Barich and Kotler's model (1991) as determinants in the image formation of universities. Based on the theoretical contribution of these authors, the objective of this study was to analyze the image of the Universidade Federal da Integração Latino-Americana - UNILA, second internal public (managers, technicians, teachers and students) and external (Foz do Iguaçu). The method with a descriptive and quantitative delineation was applied to 207 people from the internal public, and 269 from the external. As a result, it was found that the image of the university in factors such as Institutional Conduct; Social Behavior; Conduct with Servers; Support Activities; Infrastructure; Products and services; Price; And, Communication, is situated as regular (internally) and bad (externally). To improve that image, actions have been suggested as implementation of a communication committee and cascading information on the IES, monitoring of reports in the media about the UNILA, use of channels closer to the external community (newspapers, radio, social media, etc.), and periodic surveys to evaluate the image according to the internal and external public.
\end{abstract}

Keywords: Image. Dimensions. UNILA. Foz do Iguaçu. 


\section{INTRODUÇÃO}

Os primeiros estudos sobre imagem originaram-se no campo do marketing na década de 1950 tendo como foco o cliente (FOX; KOTLER, 1994). Gradativamente, pesquisadores como Lindquist (1974), Barich e Kotler (1991), Reis (1991), Iasbeck (1999) e Machado (2001), estenderam essa preocupação mercadológica à imagem corporativa, pública, pessoal, de marca e de serviços. Constatou-se, então, que os consumidores adquiriam produtos e serviços não apenas pelos seus atributos, mas também pela imagem que a empresa possuía no mercado; ou seja, a imagem adquiriu personalidade própria (TAVARES, 1998).

Sob essa perspectiva, a imagem tem se consolidado como um fator importante no desenvolvimento e manutenção das organizações, ou como argumenta Czinkota (2001) é um meio de produzir atitudes favoráveis, possibilitando não só a conquista de um diferencial competitivo, mas também a oportunidade de minimizar ameaças dos concorrentes.

Por essa razão, posicionamentos positivos que permitam que as organizações se distingam umas das outras diante de seus diversos públicos são fundamentais (CARRIERI; ALMEDIDA; FONSECA, 2004). Desse modo, construir e manter uma boa imagem não constitui um fim em si mesmo (BARBOSA, 2008), devendo ser reflexo de bons produtos e serviços, de pessoas comprometidas e de um desempenho favorável (REIS, 1991).

As Instituições de Ensino Superior (IES), especialmente as Universidades Federais, também devem considerar que a construção de sua imagem tem função estratégica (VALERIO; PIZZINATTO, 2003), uma vez que o papel destas extrapola o ensino, pesquisa e extensão, e alcança o contexto social em que estão inseridas (BRASIL, 1996).

Nessa cadeia de relacionamentos, uma imagem pode influenciar, direta ou indiretamente, em vários aspectos, desde a qualidade do ensino, uma vez que pode levar a um menor ou maior comprometimento dos alunos, até determinar a capacidade em obter recursos humanos e financeiros e estimular e manter a aliança com os seus membros (PFEFFER, 1981).

No caso da Universidade Federal da Integração Latino-Americana (UNILA), a mensuração de sua imagem representa a avaliação do cumprimento de seu papel social, uma vez que a IES se apresenta como pioneira no debate da integração solidária e na busca de soluções democráticas para os países latino-americanos (RICOBOM, 2010).

Além disso, a avaliação do público interno representará a percepção atual dos gestores, docentes, técnicos administrativos e alunos sobre a IES; do ponto de vista externo, 
possibilitará um resgate da visão negativa gerada, na comunidade local, por casos de vandalismo, furtos e drogas noticiados nos veículos de comunicação. Assim, considerando que a imagem é um dos elementos que agregam riqueza e valor, percebê-la e analisá-la na UNILA representa uma oportunidade de corrigir o rumo de sua atuação.

Nessa perspectiva, tendo como ponto de partida o modelo de Barich e Kotler (1991), que aborda os fatores e atributos que influenciam a imagem, esse estudo busca responder à seguinte problemática: Qual a imagem da UNILA segundo seu público interno e externo?

Desse modo, este artigo está estruturado em quatro seções adicionais a essa. A seção 2 apresenta o aporte teórico; a seção 3 detalha a metodologia; a seção 4 apresenta os resultados e, a seção 5, as considerações finais, limitações e sugestões para pesquisas futuras.

\section{FUNDAMENTAÇÃO TEÓRICA}

Nesse capítulo, apresentam-se conceitos sobre identidade, imagem, processo de formação e modelos de avaliação de imagem, incluindo a proposta de Barich e Kotler (1991).

\subsection{IDENTIDADE}

A identidade traduz-se em imagem (GARBETT, 1988). Ao passo que a primeira sempre irá responder à questão auto reflexiva de "quem somos" (CARRIERI; ALMEIDA; FONSECA, 2004), a segunda relaciona-se com uma representação, uma percepção pública (GOMES, 2004). Logo, "identidade, mais que imagem, refere-se ao plano real. Imagem conota uma representação disto" (TORQUATO, 2015, p. 97).

Para Andrade (2008), a identidade é a impressão digital, a qual pode ser comparada a um código genético único. Desse modo, engloba aspectos tangíveis e intangíveis, como missão, visão, valores, operações, normas e regulamentos, clima e cultura organizacionais. Por ser composta por diferentes características, que formam a personalidade institucional (TORQUATO, 2002), é inviável representá-la por inteiro por meio de um único indicador.

Vilaça (2003) acrescenta que a identidade é, simultaneamente, uma forma singular e plural de se posicionar em relação aos outros. É, portanto, um fenômeno complexo que pode variar de acordo com o contexto e público para o qual é expressa, sendo inerentemente dinâmica e tida como ponto de partida da imagem organizacional (GIOIA, 2000; TORQUATO, 2002). 
Logo, enquanto a identidade exerce forte papel interno, uma vez que ajuda a organização a entender o que é apropriado, legítimo e adequado (ELSBACH; KRAMER, 1996; RAVASI; VAN REKOM, 2003), a imagem tem um olhar mais externo, pois, por meio do uso adequado dos símbolos e artefatos, é possível alterar o nível de conscientização sobre o que a organização deseja expressar aos grupos internos e externos, conferindo diferenciação e reposicionamento (ANSPACH, 1983). Dessa forma, pode-se afirmar que a imagem é o resultado de diversos atributos que se somam, às vezes, com um efeito sinérgico (VALERIO; PIZZINATTO, 2003).

\subsection{IMAGEM E SEU PROCESSO DE FORMAÇÃO}

Imagem é a soma de crenças, ideias e impressões que uma pessoa tem de um objeto ou organização (BARICH; KOTLER, 1991). Para Reynolds e Gutman (1984), é um conjunto de significados hierarquicamente organizados e armazenados na memória que o indivíduo utiliza para descrever, relembrar e se relacionar (DOWLING, 1986). Desse modo, refere-se a uma representação mental de um conjunto de atributos e valores que funcionam como um estereótipo (COSTA, 2001) ou projeção pública (ou eco) da identidade (TORQUATO, 2002).

Sob esse panorama, um mesmo fenômeno ganhará uma interpretação para cada indivíduo, fruto de um aglomerado de impressões, convicções, rastros de memória e sentimentos em diferentes intensidades e de grande teor subjetivo (IASBECK, 1999). Portanto, "a imagem pode ser mais ou menos verdadeira, mais ou menos precisa, mais ou menos saliente, mais ou menos significante" (ALMEIDA, 2005, p. 58).

Por conseguinte, a importância desta transcende a qualidade real de uma instituição, a qual frequentemente é menos importante que seu prestígio ou reputação (VALERIO; PIZZINATTO, 2003). Desse modo, o diferencial não precisa estar, necessariamente, no produto ou serviço em si, mas sim na mente do consumidor (FOX; KOTLER, 1994).

Embora existam diferentes classificações, o conceito utilizado nesse estudo é a institucional ou corporativa, a qual se refere à forma como as pessoas veem a organização como um todo (BARICH; KOTLER, 1991), sendo o resultado das interações, experiências, impressões, sentimentos e conhecimento que as pessoas possuem dela (TAVARES, 1998).

Nesse cenário, o processo de formação de imagem tem como ponto de equilíbrio duas teorias opostas: a objetiva, que reúne experiências com objetos percebidos por meio de dados sensoriais, e a subjetiva, que é determinada pelo indivíduo, que a percebe seletivamente sob 
diferentes aspectos e graus (ANTUNES, 2004). Por esta razão, declara-se que uma organização não possui apenas uma, mas várias imagens, dependendo dos objetos específicos que estão sendo avaliados e do público envolvido (BARICH; KOTLER, 1991).

De modo complementar, Aaker (1998) aponta que a imagem está estreitamente relacionada à maneira pela qual a organização deseja ser percebida por seu mercado-alvo. Se houver uma ligação íntima com atributos favoráveis como qualidade, valor, inovação, poderá ser construído um relacionamento duradouro com o público, o qual se traduzirá em reputação (TAVARES, 1998). Contudo, nem sempre as ações organizacionais são igualmente visíveis e apreciadas por todos os seus grupos. A expectativa de alguns indivíduos pode chocar-se com as de outros, ocasionando efeitos indesejáveis, como a formação de imagens inconsistentes e até conflitantes entre diversos públicos (GEE, 1991). Quando isso ocorre, é imperativo que a instituição gerencie sua imagem e a compatibilize com a identidade (TORQUATO, 2002).

Sob essa perspectiva, a imagem de uma organização ocupa o âmago de vários construtos de atitudes que afetam e são afetados por ela. Estes podem conduzir ao fortalecimento dos pontos positivos e mitigação dos negativos, intensificando a imagem institucional (KOTLER, 1998) e as relações da instituição com seus públicos. Desse modo, avaliar constantemente a percepção destes grupos é fundamental para a manutenção e consolidação das organizações.

\subsection{PESQUISAS DE AVALIAÇÃO DE IMAGEM E SEUS ATRIBUTOS}

Embora muitas instituições efetuem estudos de imagem, poucas o fazem de maneira sistemática (BARICH; KOTLER, 1991). No caso das IES, tais pesquisas são escassas. Autores como Valerio e Pizzinatto (2003), por exemplo, analisaram a imagem de cinco universidades paulistas a partir de uma matriz de familiaridade-favorabilidade. Meyer (2002), baseada nas teorias de imagem, identidade e percepção, estudou a imagem do Centro Universitário do Leste de Minas Gerais sob a ótica de seus alunos. Por sua vez, Antunes (2004) avaliou a imagem do Instituto de Ensino Superior FUCAPI - CESF na opinião de seus principais públicos internos e externos, de acordo com o modelo de imagem de Barich e Kotler (1991).

Grohmann, Alvarenga e Venturini (2007), baseados no modelo de percepção de Borges-Andrade e Pilati (2000), identificaram a imagem de uma IES privada do Rio Grande do Sul na opinião de alunos, funcionários e professores. Já Almeida e Almeida (2008) em 
seus estudos verificaram o alinhamento entre a imagem da PUC Minas e suas unidades, segundo os alunos de Administração e Direito. Já Andrade (2008) analisou os atributos de imagem percebidos por alunos, professores, funcionários e gestores do Instituto de Ciências Sociais Aplicadas - ISAB.

A seu turno, Ferraz, Souza e Verdinelli (2009) analisaram a imagem de uma universidade do Meio Oeste Catarinense e sua relação com a satisfação segundo os egressos da IES. Viana, Coelho e Rêgo (2011) investigaram a imagem da Universidade Federal do Piauí na mídia impressa e eletrônica piauiense. Similarmente, Oliveira (2014) pesquisou como é gerenciada a imagem organizacional nas redes sociais de três IES de Minas Gerais.

Moraes et al. (2014) analisaram a percepção da imagem das IES de Manhuaçu-MG, de acordo com os habitantes da região. Por sua vez, Villela Filho (2015) mensurou a imagem de uma IES privada e as relações dela com o marketing, sob a perspectiva dos alunos.

Diante das inúmeras possibilidades para avaliar a imagem institucional, o modelo de fatores e atributos elaborado por Barich e Kotler (1991) possibilita uma visão global da organização, visto que seus componentes são aspectos controláveis do composto mercadológico (finanças, marketing, estratégia, responsabilidade social, gestão de pessoas).

Nesse contexto, esclarece-se que, apesar da imagem ser um todo indivisível (BARBOSA, 2008), identificar os elementos responsáveis por sua formação e como estes se relacionam é fundamental para estabelecer como a organização quer ser vista e reconhecida (TAVARES, 1998), porquanto se cada um destes atributos for analisado separadamente, será possível desenvolver estratégias eficazes para melhorar sua imagem (MEYER, 2002).

Assim, a imagem, segundo Barich e Kotler (1991), pode ser formada por 11 dimensões: Conduta Social da Empresa; Conduta de Negócios; Força de Vendas; Canais de Distribuição; Serviço; Suporte, Preço, Comunicação, Produto, Conduta Empresarial com Empregados e Filantropia. No caso das IES, esses elementos ganham roupagem adaptada focada no marketing educacional e no relacionamento com diversos públicos - professores, alunos, funcionários e público em geral (BERNSTEIN, 1991). Desse modo, os fatores formadores de imagem podem ser sintetizados em 8 vertentes: Conduta Institucional; Conduta Social; Conduta com Servidores; Atividades de Suporte; Infraestrutura; Produtos e Serviços; Preço; e, Comunicação.

A Conduta Institucional compreende a estratégia, inovação, ética e boas práticas de governança (BARICH; KOTLER, 1991). A Conduta Social representa o compromisso da 
organização com a sociedade, expresso por ações que a afetem positivamente (ASHLEY et al., 2003). A Comunicação é influenciada pela publicidade e pela propaganda veiculada na mídia, ou seja, pelas informações recebidas sobre a organização (VANCE; ANGELO, 2007).

Por sua vez, a Conduta com Servidores abrange características centrais e duradouras que influenciam as atitudes e carreira dos colaboradores (DUTTON; DUKERICH, 1991). Quanto à Infraestrutura, esta corresponde aos atributos físicos e materiais necessários ao funcionamento das atividades educacionais, tais como instalações e localização (ANTUNES, 2004). No que tange ao Preço, este não se relaciona exclusivamente com valores monetários, uma vez que as IES públicas são gratuitas, mas sim a um processo de compra, no qual uma imagem negativa pode resultar em perda de alunos (DESCHAMPS; NAYAK, 1996).

O fator Produtos e Serviços abrange os cursos de graduação e pós-graduação ofertados à comunidade, sendo incluídos como atributos o seu conteúdo e qualidade (ANTUNES, 2004). Por fim, as Atividades de Suporte têm relação com programas e projetos oferecidos para o público interno, mas que possuem reflexo na comunidade externa (KOTLER; FOX, 1994).

No entanto, Barich e Srinivasan (1993) destacam que nenhuma instituição consegue manter elevadas todas as suas dimensões de imagem ao mesmo tempo, e, portanto, precisam descobrir quais de seus atributos são considerados mais relevantes segundo seu público e estimar o custo para manter ou melhorar a imagem institucional.

Nesse contexto, como a formação da imagem deve ser encarada como um trabalho permanente e planejado (VALERIO; PIZZINATTO, 2003), a verificação dos construtos que influenciam a imagem da UNILA constitui o primeiro passo para a criação, manutenção e reformulação de uma reputação favorável à universidade (EINWILLER; WILL, 2002), pois conforme afirma Andrade (2008), convém ao público estar no "time" que oferece maior valor.

\section{PROCEDIMENTOS METODOLÓGICOS}

A abordagem escolhida para essa pesquisa foi a quantitativa (ROESCH, 2009), por meio de um survey (levantamento) aplicado internamente, junto aos gestores, professores, técnicos administrativos e alunos da universidade, e externamente, junto à população de Foz do Iguaçu.

Para a coleta de dados, utilizou-se questionário adaptado do modelo proposto por Barich e Kotler (1991), composto por 3 questões abertas e 32 fechadas, estas últimas com 
escala intervalar de 7 pontos. O Quadro 1 apresenta as variáveis utilizadas no instrumento de pesquisa.

Quadro 1 Delimitação das variáveis

\begin{tabular}{|c|c|c|c|}
\hline Objetivo & Autor & Dimensão & Variáveis \\
\hline $\begin{array}{l}\text { Diagnosticar o } \\
\text { perfil do público } \\
\text { interno } \\
\text { externo }\end{array}$ & $\begin{array}{l}\text { Kotler } \\
(1994)\end{array}$ & $\begin{array}{l}\text { Caracterização } \\
\text { da amostra }\end{array}$ & $\begin{array}{l}\text { Interno: Categoria, Idade, Gênero, Língua Materna, } \\
\text { Procedência Geográfica. } \\
\text { Externo: Idade, Gênero, Região, Renda }\end{array}$ \\
\hline \multirow{8}{*}{$\begin{array}{l}\text { Verificar } \\
\text { fatores } \\
\text { atributos } \\
\text { imagem de } \\
\text { presentes na IES }\end{array}$} & \multirow{8}{*}{$\begin{array}{l}\text { Barich e } \\
\text { Kotler } \\
(1991)\end{array}$} & $\begin{array}{l}\text { Conduta } \\
\text { institucional }\end{array}$ & $\begin{array}{l}\text { Reputação na sociedade, inovação, qualidade da gestão, } \\
\text { integração com outras instituições }\end{array}$ \\
\hline & & Conduta social & $\begin{array}{l}\text { Atuação e relacionamento com a comunidade, } \\
\text { desenvolvimento de ações sociais e culturais }\end{array}$ \\
\hline & & $\begin{array}{l}\text { Conduta com } \\
\text { servidores }\end{array}$ & $\begin{array}{l}\text { Políticas de estímulo ao aprimoramento e desenvolvimento } \\
\text { pessoal e profissional e plano de carreira. }\end{array}$ \\
\hline & & $\begin{array}{l}\text { Atividades de } \\
\text { suporte }\end{array}$ & $\begin{array}{l}\text { Participação em programas de estágio e iniciação } \\
\text { científica, em atividades acadêmicas e atendimento ao } \\
\text { público }\end{array}$ \\
\hline & & Infraestrutura & Localização, Instalações \\
\hline & & $\begin{array}{l}\text { Produtos } \\
\text { serviços }\end{array}$ & $\begin{array}{l}\text { Especificidade e qualidade dos cursos, adequação da } \\
\text { formação ao mercado de trabalho }\end{array}$ \\
\hline & & Preço & $\begin{array}{l}\text { Auxílios financeiros e sociais concedidos pela IES, custo } \mathrm{x} \\
\text { benefício do ensino fornecido }\end{array}$ \\
\hline & & Comunicação & Eficácia da comunicação e percepção da marca \\
\hline
\end{tabular}

Fonte: Elaborado pelos autores (2016).

As questões foram inicialmente validadas por meio de pré-teste (ROESCH, 2009) e o questionário foi aplicado, via Google Formulários, durante os dias 26 de abril a 19 de maio de 2016 para o público interno, e durante os dias 5 de maio a 8 de agosto de 2016 para o externo.

De um universo interno de 3.938 pessoas, aderiram ao estudo um montante de 207. Externamente, em um universo de 263.915 pessoas (IBGE, 2016) aderiram à pesquisa 269 indivíduos. As amostras, embora não probabilísticas, atenderam aos critérios defendidos por Hair et al. (2006), de que o número mínimo de observações por variável deve ser superior a 5.

A análise dos resultados foi baseada em técnicas estatísticas univariadas e multivariadas. Inicialmente, realizou-se a caracterização do perfil dos respondentes por meio de distribuição de frequências. Na sequência, foi avaliada a normalidade dos dados por meio de testes de curtose, assimetria e desvio padrão, a fim de verificar a aderência das variáveis à uma distribuição normal ou de Gauss (SIEGEL, 1979). Para tanto, foram admitidos valores de curtose e assimetria entre \pm 3 , conforme indicado por Schumacker e Lomax (2004).

Em paralelo, efetuou-se o teste do Alfa de Cronbach para avaliar a confiabilidade do instrumento de pesquisa, considerando como satisfatórios valores acima de 0,70 (HAIR et al., 2006). Por fim, estabeleceu-se a média geral dos fatores e atributos de imagem, a fim de 
verificar as variáveis com maior poder de influência no construto imagem institucional. Os testes estatísticos foram realizados no software SPSS versão 23.

\section{CARACTERIZAÇÃO DA IES E ANÁLISE DOS RESULTADOS}

A Universidade Federal da Integração Latino-Americana (UNILA) apresenta-se como pioneira no fortalecimento dos processos de integração da América Latina, de valorização e ressignificação do continente e do povo latino-americano (RICOBOM, 2010). Implantada em 2010, pelo Ministério da Educação (MEC), por meio da Lei $\mathrm{n}^{\circ} 12.189$, na cidade de Foz do Iguaçu - Paraná, a IES foi planejada para ser "sem fronteiras" (CORAZZA, 2010).

Com projeto pedagógico inovador, corpo docente e discente formado por brasileiros e latino-americanos, a UNILA oferece 29 cursos de graduação e 10 de pós-graduação, desenvolve 326 projetos de pesquisa e 199 ações de extensão (UNILA, 2016). Ao todo, são 868 servidores para dar suporte aos mais de 3.070 alunos. A IES ainda não possui campus próprio e distribui suas atividades em 5 unidades (PTI, Almada, Vila A, Almoxarifado e Jardim Universitário).

Em relação à qualidade dos cursos de graduação e programas de pós-graduação, a UNILA obteve a terceira colocação no Índice Geral de Cursos (IGC/MEC, 2016), ficando atrás apenas da Unicamp e UFRGS (UNILA, 2016).

\subsection{ANÁLISE DOS FATORES E ATRIBUTOS DA IMAGEM INSTITUCIONAL}

Após a contextualização da IES e visando atender ao primeiro objetivo deste estudo, efetuou-se a caracterização da amostra do público interno (gestores, docentes, técnicos e alunos) da UNILA. Do total de 207 amostras válidas, constatou-se um equilíbrio quanto ao gênero dos respondentes: $48 \%$ são do sexo masculino, $47 \%$ do feminino e $5 \%$ preferiu não responder à questão. Em relação à faixa etária, 32\% possuem até 24 anos, 41\% dos pesquisados têm entre 25 e 34 anos, 32\% possuem idade entre 35 e 49 anos, e 4\% estão na faixa acima de 50 anos.

No que diz respeito à origem geográfica, os respondentes foram, em sua maioria (90\%) de brasileiros, vindos dos estados do Paraná, São Paulo, Minas Gerais, Santa Catarina, Rio Grande do Sul, Bahia, Pernambuco, Goiás, Pará Alagoas, Amazonas e Mato Grosso. Do restante dos respondentes, $8 \%$ são de países latino-americanos (Colômbia, Argentina, Equador, Peru, El Salvador, Uruguai, México e Bolívia) e 2\% não respondeu à questão. 
Quanto à identificação dos pesquisados por categoria, do total de 207 amostras, 53\% são técnicos administrativos, 29\% alunos, 11\% docentes e 7\% gestores. A Tabela 1 apresenta o universo e amostra do público interno formado por gestores, técnicos administrativos, docentes e alunos.

Tabela 1 Perfil do público interno por categoria

\begin{tabular}{lccc}
\hline Categoria & Universo & Amostra & \% da Amostra / Universo \\
\hline Gestão & 44 & $\mathbf{1 5}$ & $34 \%$ \\
Técnico Administrativo & 516 & $\mathbf{1 0 9}$ & $21 \%$ \\
Docente & 352 & $\mathbf{2 3}$ & $7 \%$ \\
Aluno & 3.070 & $\mathbf{6 0}$ & $2 \%$ \\
Total geral & $\mathbf{3 . 9 3 8}$ & $\mathbf{2 0 7}$ & $\mathbf{5 \%}$ \\
\hline
\end{tabular}

Fonte: Elaborado pelos autores (2016).

$\mathrm{Na}$ sequência, foi realizada a caracterização do público externo, formado por moradores de Foz do Iguaçu. Das 269 amostras coletadas, 56\% são do gênero feminino, 43\% do masculino e 1\% preferiu não responder. Em relação à faixa etária, 16\% têm até 24 anos, $30 \%$ têm entre 25 e 34 anos, $41 \%$ têm idade entre 35 e 49 anos, e 12\% estão na faixa acima de 50 anos. Quanto à faixa salarial, 23\% recebem até 2 salários mínimos, 31\% entre 2 e 4 salários, 34\% entre 4 e 10 salários, $10 \%$ entre 10 e 20 salários mínimos e apenas $2 \%$ recebem acima de 20 salários.

No que diz respeito à região dos respondentes, todas foram abrangidas pela pesquisa, com destaque para a 8 e 9, com maior percentual de participação, como ilustrado na Tabela 2.

Tabela 2 Perfil do público externo por região de Foz do Iguaçu

\begin{tabular}{lcc}
\hline Regiões do município de Foz do Iguaçu & Amostra & \% da amostra por região \\
\hline R1 - Região das Três Lagoas & 9 & $3 \%$ \\
R2 - Região da Vila "C” & 31 & $12 \%$ \\
R3 - Região do São Francisco & 12 & $4 \%$ \\
R4 - Região do Porto Meira & 14 & $5 \%$ \\
R5 - Região do Jardim São Paulo & 25 & $9 \%$ \\
R6 - Região do Jardim América & 13 & $5 \%$ \\
R7 - Região do Imperatriz & 23 & $9 \%$ \\
R8 - Região da Vila A & 52 & $19 \%$ \\
R9 - Região Central & 59 & $22 \%$ \\
R10 - Região do Campos do Iguaçu & 23 & $9 \%$ \\
R11 - Região da Vila Carimã & 3 & $1 \%$ \\
R12 - Região Rural & 5 & $2 \%$ \\
Total & $\mathbf{2 6 9}$ & $\mathbf{1 0 0 \%}$ \\
\hline
\end{tabular}

Fonte: Elaborado pelos autores (2016).

Caracterizado os perfis do público interno e externo, iniciou-se a verificação dos fatores e atributos que mais contribuíam para a formação da imagem da UNILA. Para tanto, 
realizou-se o teste de confiabilidade do instrumento de pesquisa por meio do Alfa de Cronbach. Apenas a dimensão Preço para o público interno não apresentou valor satisfatório acima de 0,70 preconizado por Hair et al. (2006). A Tabela 3 apresenta o detalhamento desse teste.

Tabela 3 Teste de confiabilidade

\begin{tabular}{lcc}
\hline Dimensão & Alfa de Cronbach - Público Interno & Alfa de Cronbach - Público Externo \\
\hline Conduta Institucional & 0,761 & 0,814 \\
Comunicação & 0,796 & 0,836 \\
Conduta Social & 0,923 & 0,898 \\
Conduta com servidores & 0,767 & 0,895 \\
Atividades de suporte & 0,815 & 0,884 \\
Infraestrutura & 0,833 & 0,847 \\
Produtos e serviços & 0,925 & 0,862 \\
Preço & 0,249 & 0,786 \\
\hline
\end{tabular}

Fonte: Elaborado pelos autores (2016).

Posteriormente, realizou-se a estatística descritiva por meio da análise do desvio padrão, assimetria e curtose. As 32 variáveis fechadas desse estudo apresentaram valores entre \pm 3 , atendendo às orientações de Siegel (1979) e Schumacker e Lomax (2004). Na sequência, efetuou-se a análise de frequências de cada atributo, conforme detalhado na Tabela 4.

Tabela 4 Médias dos atributos de imagem em relação ao público interno e externo

\begin{tabular}{lcc}
\hline Dimensões e atributos & $\begin{array}{c}\text { Público } \\
\text { interno }\end{array}$ & $\begin{array}{c}\text { Público } \\
\text { externo }\end{array}$ \\
\hline Dimensão Conduta Institucional & $\mathbf{4 , 1 2}$ & $\mathbf{3 , 9 3}$ \\
1. A UNILA possui reputação positiva na sociedade. & 3,48 & 3,92 \\
2. A UNILA possui perfil de instituição inovadora (do ponto de vista de integração entre & 5,28 & 4,66 \\
países, cursos, projeto pedagógico, estrutura organizacional). & & \\
$\begin{array}{l}\text { 3. A UNILA possui uma gestão de qualidade (preocupada com administração geral, } \\
\text { ensino e pesquisa, e comprometida com a missão institucional). }\end{array}$ & 3,74 & 3,61 \\
$\begin{array}{l}\text { 4. A UNILA interage com outras instituições públicas e privadas, visando a realização de } \\
\text { parcerias e projetos. }\end{array}$ & 3,97 & 3,55 \\
$\begin{array}{l}\text { Dimensão Comunicação } \\
\text { 5. A comunicação da UNILA com seu público interno (técnicos, docentes e gestão) é } \\
\text { eficaz. }\end{array}$ & $\mathbf{3 , 5 4}$ & $\mathbf{3 , 5 3}$ \\
$\begin{array}{l}\text { 6. A divulgação da UNILA e de suas ações para o público externo (local, regional, } \\
\text { nacional e internacional) é eficaz. }\end{array}$ & 3,50 & 2,47 \\
7. A marca UNILA proporciona status aos alunos e servidores (docentes e técnicos & 3,23 & 4,02 \\
administrativos) junto à sociedade. & & \\
$\begin{array}{l}\text { 8. A Imagem da UNILA (interna e externa) é de instituição de ensino superior de } \\
\text { qualidade }\end{array}$ & 3,94 & 4,10 \\
$\begin{array}{l}\text { Dimensão Conduta Social } \\
\text { 9. A UNILA preocupa-se com a comunidade realizando ações sociais e culturais. }\end{array}$ & $\mathbf{4 , 5 8}$ & $\mathbf{3 , 6 8}$ \\
$\begin{array}{l}\text { 10. A UNILA investe em atividades de interesse da comunidade acadêmica e externa } \\
\text { (cursos, eventos, ações culturais e sociais). }\end{array}$ & 4,65 & 3,70 \\
$\begin{array}{l}\text { 11. Os alunos da UNILA são envolvidos com as atividades acadêmicas e em projetos } \\
\text { externos de interesse da comunidade. }\end{array}$ & 4,52 & 3,18 \\
\end{tabular}


Dimensões e atributos
12. A UNILA possui perfil de instituição integradora (do ponto de vista de integração da

América Latina e da universidade com a comunidade local de Foz do Iguaçu).

Dimensão Conduta com servidores

Público Público

interno externo

13. O quadro funcional (docentes, técnicos administrativos e gestão) atende às necessidades organizacionais.

14. O quadro funcional (docentes, técnicos administrativos e gestão) é qualificado.

15. A UNILA estimula a alocação, capacitação e desenvolvimento de carreira do quadro funcional (docentes, técnicos administrativos e gestão) alinhados à missão institucional.

16. A UNILA consegue manter seu quadro funcional (docentes, técnicos administrativos e gestão) motivado.

Dimensão Atividades de Suporte

$4,31 \quad 4,07$

17. A Gestão da UNILA tem envolvimento com as atividades acadêmicas.

$3,94 \quad 2,90$

$4,06 \quad 2,77$

$4,93 \quad 3,84$

$3,71 \quad 2,60$

$3,04 \quad 2,40$

18. A UNILA incentiva a participação dos servidores (docentes, técnicos administrativos e gestão) em projetos (cursos, eventos) internos e externos.

19. A UNILA incentiva a participação dos alunos em programas de iniciação científica, estágios e outras ações acadêmicas.

20. Os servidores da UNILA (docentes, técnicos administrativos e gestão) são prestativos, corteses, comprometidos com prazos e qualidade no atendimento interno e externo.

Dimensão Infraestrutura

21. A UNILA possui instalações adequadas (salas de aulas, laboratórios, biblioteca e outros espaços acadêmico-administrativos) para sua finalidade.

22. Os serviços prestados pela UNILA (transporte, manutenção, logística, entre outros) são satisfatórios.

23. A localização das unidades da UNILA (Vila A, Almada, Almoxarifado, Jardim Universitário e PTI) é satisfatória

24. A política de expansão de espaços da UNILA supre as necessidades institucionais.

Dimensão Produtos e Serviços

25. A UNILA oferece cursos de graduação e pós-graduação inovadores.

26. A UNILA oferece cursos de graduação e pós-graduação de qualidade.

27. O profissional egresso (formado) da UNILA tem boa receptividade no mercado de trabalho.

28. O diploma da UNILA tem grande valor junto ao mercado de trabalho.

Dimensão Preço

29. A gratuidade do ensino é um fator que influencia a decisão da escolha da instituição.

30. Os auxílios concedidos aos alunos da UNILA são fatores que influenciam a decisão da escolha da instituição.

31. A inexistência ou redução dos auxílios reduziria o número de alunos da UNILA.

32. A relação custo/benefício que a UNILA proporciona aos alunos é satisfatória.

Média geral em relação a todas as dimensões

$\mathbf{3 , 7 7} 2,92$

$3,01 \quad 2,67$

$3,67 \quad 2,77$

$4,29 \quad 3,19$

$4,13 \quad 3,05$

$3,97 \quad 3,16$

$4,12 \quad 3,36$

$4,29 \quad 2,83$

$4,12 \quad 3,80$

$3,34 \quad 2,66$

$\mathbf{3 , 4 9} \quad 3,65$

$4,72 \quad 4,23$

2,25 3,91

$2,28 \quad 3,02$

$3,84 \quad 3,43$

$\mathbf{5 , 1 9} \quad \mathbf{4 , 8 4}$

$5,75 \quad 5,62$

$5,29 \quad 4,87$

$5,17 \quad 4,73$

$4,56 \quad 4,12$

$\mathbf{4 , 0 7} \mathbf{3 , 5 7}$

Fonte: Elaborado pelos autores (2016).

Em princípio, percebe-se que nenhuma variável alcançou média próxima ao "maior valor possível", representado pela nota 7, tendo sido atribuída à dimensão Preço a melhor avaliação pelo público interno e externo, e aos construtos Produtos e Serviços e Conduta com Servidores, o pior desempenho, segundo o público interno e externo, respectivamente.

Em uma escala qualitativa de posicionamento de imagem, representada, por exemplo, por ruim (médias até 3,9), regular (médias entre 4,0 e 4,9), bom (médias entre 5,0 e 5,9), e ótimo (médias acima de 6,0), verifica-se que a média geral das 8 dimensões situou a UNILA 
na faixa "ruim" para o público externo, e "regular" para o interno. Esse resultado revela a dificuldade da IES na criação de uma imagem sólida e positiva na mente de seu público, conforme indicado por Antunes (2004) e evidencia a necessidade de ações estratégicas no sentido de se criar uma imagem mais atraente aos olhos destes grupos, conforme orientam Barich e Srinivasan (1993).

Analisando-se cada variável, percebe-se que, na dimensão Conduta Institucional, ambos os públicos reconheceram o perfil inovador da UNILA enquanto integração entre países latino-americanos, cursos, projeto pedagógico e estrutura organizacional. Como contraponto, a interação da IES com outras instituições e a reputação na sociedade foram mal avaliadas pelo público externo e interno, respectivamente. No caso da reputação verifica-se que, se a percepção do público interno sobre a IES não é positiva, a visão externa da UNILA pode ser ainda mais prejudicada. Desse modo, faz-se necessário comunicar melhor a IES, ouvir o que a comunidade conhece e assimila sobre a universidade, sobretudo por meio das notícias veiculadas na mídia, e transformar as informações coletadas em um instrumento a seu favor (KOTLER, 2001).

Em relação à dimensão Comunicação, os moradores de Foz do Iguaçu assinalaram que a comunicação interna da IES é ineficaz. Do ponto de vista interno, a pior avaliação está relacionada ao status provocado pela marca UNILA junto à sociedade. Positivamente, ambos os públicos indicaram que a imagem da IES é de uma instituição de qualidade.

Contudo, apesar desse último indicativo positivo, observa-se a necessidade de que a IES melhore sua comunicação e o relacionamento com a comunidade interna e externa e crie oportunidades de troca de informações entre os públicos, evitando que uma imagem geral negativa da universidade faça com que ela seja desprestigiada ou evitada, mesmo se que ela seja de qualidade (KOTLER; FOX, 1994).

Nesse cenário, a preocupação em comunicar e gerar boa imagem deve começar internamente, pois conforme apontam Kotler e Fox (1994), um processo de comunicação só será eficaz se concentrar seus esforços na criação de uma identidade forte. Assim será possível que a UNILA crie ações mais consistentes, capte a atenção do público, influencie positivamente seu comportamento e o transforme no melhor divulgador da IES (MACHADO, 2001).

Em relação à Conduta Social, o público interno destaca que a IES tem preocupação com a sociedade por meio de ações sociais e culturais, enquanto que a comunidade externa 
evidencia que a universidade possui perfil integrador. Como contraponto, os docentes, técnicos e alunos entendem que essa integração não é tão evidente, e o público externo sente necessidade de maior envolvimento dos alunos em ações acadêmicas de interesse do município, como estágios e eventos. Sob esse panorama, novamente, uma comunicação eficaz pode evidenciar ao público externo as ações da IES desenvolvidas para a comunidade, podendo transformar a imagem da universidade enquanto cidadã (BARICH; SRINIVASA, 1993).

No que diz respeito ao construto Conduta com Servidores, os dados revelaram que ambos os públicos acreditam que a UNILA não consegue manter seu quadro funcional (docentes, gestores e técnicos administrativos) motivado. Paralelamente, os resultados demonstraram também que, apesar da ausência de motivação, os colaboradores são qualificados. Logo, verifica-se a necessidade de atenção às políticas de gestão de pessoas, as quais podem contribuir para o desenvolvimento, manutenção e motivação dos servidores na IES (DUTTON; DUKERICH, 1991), bem como fortalecer a identidade institucional.

Quanto à dimensão Atividades de Suporte, a melhor avaliação refere-se ao fato de que a IES estimula a participação dos alunos em programas de iniciação científica, estágios e outras atividades acadêmicas. Por outro lado, foi assinalado por ambos os públicos que a gestão da universidade possui baixo envolvimento com essas atividades acadêmicas. Novamente, verifica-se que um processo de comunicação institucional adequado poderia contribuir para a divulgação das ações desempenhadas efetivamente pela IES.

Em relação ao construto Infraestrutura, os dados revelaram que a política de expansão espaços não vem suprindo as necessidades institucionais, o que pode ter relação com a ausência de campus próprio da IES, cuja construção encontra-se paralisada por questões legais e contratuais, comprometendo o atendimento total de demandas de salas de aulas, laboratórios, restaurante estudantil, entre outros (ANTUNES, 2004). Contudo, segundo o público interno, os demais serviços prestados pela IES (transporte, manutenção, logística e outros) são satisfatórios; ao passo que, segundo a comunidade externa, a localização das unidades administrativas e acadêmicas no município de Foz do Iguaçu também é satisfatória.

Sobre os Produtos e Serviços da IES, a maior média para ambos os públicos se refere aos cursos de graduação e pós-graduação serem considerados inovadores. Por outro lado, destaca-se que o público interno entende que tais cursos, apesar de inovadores, não são de qualidade, e o público externo assinala que a receptividade do egresso no mercado não é boa. 
Esses resultados podem ter relação com a oferta de cursos com nomenclaturas e abordagens pouco usuais com foco na América Latina. Assim, percebe-se que, embora a implantação de cursos temáticos tenha sido uma estratégica para captar alunos estrangeiros, ao mesmo tempo, pode ter comprometido o interesse de brasileiros, porquanto, culturalmente, está arraigado em nosso ensino superior formações mais tradicionais (RODRIGUES, 2000).

No que diz respeito à dimensão Preço, todas as variáveis foram bem avaliadas e apresentaram as maiores médias da pesquisa. Nesse sentido, verifica-se que a gratuidade é um fator de grande influência na decisão da escolha da universidade para ambos os públicos. Importante destacar que esse resultado não diz respeito apenas à não incidência de mensalidades (ANTUNES, 2004), mas também à existência ou não de políticas assistenciais estudantis - como bolsas, moradia, e outros auxílios - para fixar os alunos da instituição.

Além dessas dimensões, foram aplicadas mais 3 questões para mensurar a imagem da UNILA. A primeira refere-se ao grau de satisfação dos respondentes sobre a IES. Para os 207 pesquisados internamente, a média geral, em um valor máximo de 7 , atingiu 4,57, ao passo que para os 269 respondentes da comunidade externa esse grau alcançou média de 4,01.

Novamente, caso fosse feita uma escala qualitativa de satisfação em que médias até 3,9 representassem "ruim"; entre 4 e 4,9 pontos, "regular"; 5,0 e 5,9 pontos, bom; e, acima de 6,0 pontos ótimo, constata-se que a satisfação de ambos os públicos com a UNILA se classifica como regular. Tal resultado se contrapõe à afirmação de Kotler e Fox (1994) de que uma instituição bem-sucedida deve lidar eficazmente com seus muitos públicos e gerar alto nível de satisfação, pois a IES ao falhar no desenvolvimento de programas satisfatórios a seus públicos, produz má repercussão boca a boca e um possível turnover de alunos.

Questionados se incentivariam alguém a estudar na UNILA, 81\% do público interno responderam que indicariam, $17 \%$ disseram que não e $2 \%$ responderam talvez. Em relação à comunidade externa, $77 \%$ incentivariam, $21 \%$ não indicariam, $1 \%$ responderam talvez e $1 \%$ preferiram não responder. Estes resultados demonstram que, apesar das avaliações medianas ou baixas em cada dimensão de imagem e no nível de satisfação geral, há uma reação afetiva ou emocional - boa e forte - dos públicos em relação à futura reputação da IES.

Do total de respostas positivas, foram identificados 9 grupos de justificativas para o incentivo a estudar na UNILA. Entre as mais pontuadas, enquadram-se a qualidade do ensino e do corpo docente $(27 \%$ segundo o público interno e $25 \%$ de acordo com a comunidade externa), o ensino gratuito/universidade federal (20\% segundo o público interno e $38 \%$ de 
acordo com a comunidade externa) e o projeto pedagógico inovador ( $18 \%$ segundo o público interno e $12 \%$ de acordo com a comunidade externa), os quais relacionam-se com as dimensões Produtos e Serviços, Preço e Conduta Institucional, respectivamente.

Das respostas negativas, foram identificados 13 grupos de justificativas. As mais citadas pelo público interno referem-se à possíveis atitudes políticas e ideológicas da IES (14\%), à desorganização acadêmica e administrativa (11\%), à falta de infraestrutura (9\%) e o fato da IES ainda estar em implantação (9\%). Para os moradores de Foz do Iguaçu, a ausência de incentivo para estudar na UNILA resulta da imagem negativa da IES (45\%) e do desconhecimento sobre a universidade (11\%), os quais podem ter relação com as notícias veiculadas na mídia ou com o estereótipo agregado aos alunos estrangeiros.

Por fim, a última questão da pesquisa foi direcionada apenas para o público externo, de modo a indicar qual a primeira imagem que vem à mente quando se pensa na UNILA. Como resultado foram identificados 63 grupos de imagens que representam a IES. Esse número, por si só, encontra explicação em Barich e Kotler (1991) que afirmam que uma organização não possui apenas uma, mas várias imagens. Os termos mais citados pelos respondentes foram Integração (13\%), Diversidade (7\%), Qualidade (7\%), Bagunça (6\%), Gratuidade (6\%), Política (4\%) e Drogas (4\%). Percebe-se também que essas imagens são ora positivas (integração, diversidade, qualidade e gratuidade), ora negativas (bagunça, política e drogas); esse resultado respalda-se em Tavares (1998) que afirma que a imagem de uma organização decorre tanto de impressões positivas e neutras quanto negativas.

Em linhas gerais, constata-se que a imagem tanto do público interno quanto externo a respeito da UNILA é muito próxima e indica um árduo caminho a ser percorrido para melhorar essa percepção. Nesse sentido, a IES pode iniciar sua estratégia de atualização da imagem por meio do desenvolvimento de ações de comunicação e divulgação, junto aos gestores, técnicos, docentes e alunos. Se esse público interno sentir orgulho da universidade, de seus valores, produtos e serviços (TAVARES, 1998), será possível obter um reforço positivo de sua identidade e, consequentemente, de sua imagem, já que esses dois elementos se complementam. 


\section{CONSIDERAÇÕES FINAIS}

Embora a avaliação da imagem de qualquer organização seja uma tarefa complexa, em razão da multiplicidade de públicos e perspectivas (crenças, ideias e impressões próprios a cada indivíduo), ela é, ao mesmo tempo, necessária.

Diante disso, esse estudo buscou identificar a imagem percebida da UNILA segundo gestores, professores, técnicos administrativos e alunos da própria IES e moradores do município de Foz do Iguaçu, a partir de 8 dimensões propostas por Barich e Kotler (1991): Conduta Institucional; Conduta Social; Conduta com Servidores; Atividades de Suporte; Infraestrutura; Produtos e Serviços; Preço; e Comunicação. O instrumento de pesquisa composto por 35 questões teve sua confiabilidade validada por meio de testes de Alfa de Cronbach, análise de desvio padrão, curtose e assimetria para cada dimensão e variável.

Como resultados, verificou-se que as médias gerais de todas as dimensões foram de 4,07 e 3,57, classificando a imagem da UNILA em "regular" para o público interno e "ruim" para o externo. O construto Preço foi o melhor avaliado, e as dimensões Produtos e Serviços e Conduta com Serviços, tiveram o pior desempenho segundo o público interno e externo, respectivamente. Quanto à satisfação dos pesquisados sobre a IES, a média geral ficou entre 4,01 (público externo) e 4,57 (público interno), classificando a UNILA como regular.

Apesar dessas avaliações baixas e medianas, a grande maioria ( $81 \%$ do público interno e $77 \%$ do externo) incentivaria outra pessoa a estudar na UNILA, pela qualidade do ensino e do corpo docente, gratuidade e projeto pedagógico inovador.

Desta perspectiva, constata-se que o elo a ser fortalecido no processo de formação de imagem da IES diz respeito à sua comunicação. Nesse sentido, são propostas algumas estratégias para melhorar o posicionamento da UNILA junto aos públicos interno e externo.

Para o público interno, uma das ações a serem implantadas refere-se ao desenvolvimento de seminários anuais, nos quais os técnicos administrativos, docentes, gestores e alunos são convidados a discutir junto à área de Comunicação Social da UNILA a estratégia e o repensar dos valores de comunicação. Essa construção conjunta e democrática tem como premissa o entendimento e o reforço da sensação de pertencimento à instituição entre os diversos níveis (identidade), influenciando ainda na melhoria do clima organizacional.

Além disso, para assegurar a melhoria contínua do processo comunicativo, sugere-se a implantação de um Comitê de Comunicação Institucional, formado por representantes de cada 
área da universidade, que se reúne mensalmente para discutir boas práticas de comunicação como escuta ativa, percepção e feedback, sugerir pautas e demandar ações específicas.

Outra sugestão é a melhoria do fluxo de informações internas, principalmente em razão da dispersão geográfica de técnicos, docentes, gestores e alunos em 5 unidades. Desse modo, a ideia central é garantir que as informações sejam distribuídas internamente no tempo adequado. Como exemplo, quando existirem decisões tomadas em nível institucional, estas podem ser repassadas por um mecanismo de cascateamento da informação, descendo ao nível inferior, que comunica ao outro, até que toda a comunidade interna seja informada. Essa transparência contribui para que o público interno saiba rapidamente o que acontece na instituição.

Também se recomenda o monitoramento de notícias divulgadas na mídia sobre a UNILA, de modo a avaliar o impacto e lidar com a repercussão negativa e positiva destas reportagens. De modo complementar, indica-se a necessidade de utilização de canais mais próximos e persuasivos junto ao público externo (moradores de Foz do Iguaçu), tais como comunicações diretas, conversas boca a boca, mídias sociais, site institucional, eventos, folders e divulgação de matérias em jornais, revistas, rádio e televisão para reforçar resultados positivos gerados pela universidade. Desse modo, poderão ser conhecidos os projetos desenvolvidos que sejam de interesse da comunidade local, contribuindo para diminuir as assimetrias quanto à imagem da UNILA e fortalecendo a formação de novas imagens acerca da IES.

Além disso, sugere-se a aplicação de pesquisas semestrais ou anuais para avaliar a imagem segundo o público interno e externo. Os resultados obtidos nesses levantamentos, possibilitarão o planejamento de ações capazes de corrigir ou incrementar melhorias nos veículos de comunicação e em cada uma das dimensões de imagem da universidade.

Diante do exposto, considera-se que esse estudo possibilita à UNILA reconhecer a percepção interna e externa de sua imagem, permitindo adequações pontuais das práticas de gestão universitária. Caso as considerações tecidas nessa pesquisa sejam implementadas, será possível maior alinhamento de imagem e, consequentemente, maior convergência com a identidade (ou realidade) institucional e a percepção da comunidade local.

Contudo, a pesquisa apresenta alguns fatores limitadores. Entre eles, estão o número de respondentes, uma vez que o ideal seria uma amostragem probabilística da universidade e dos moradores de Foz do Iguaçu; e o corte transversal do estudo, cuja avaliação ocorrida em 
um único momento, não permitiu analisar as possíveis variações que pudessem ocorrer em diferentes momentos.

Assim, como sugestão de pesquisas futuras, recomenda-se a realização de estudos longitudinais para analisar as variações nas caraterísticas dos mesmos elementos amostrais ao longo do tempo. Sugere-se também a ampliação da mensuração da imagem da UNILA, tendo como público as comunidades dos países latino-americanos que possuem alunos na instituição para verificar como a IES é percebida na América Latina.

\section{REFERÊNCIAS}

AAKER, D. A. Marcas: brand equity - gerenciando o valor da marca. São Paulo: Negócio Editora, 1998.

ALMEIDA, A. L. de C. A Construção da reputação organizacional. 2005. 361 f. Tese de Doutorado (Centro de Pós-Graduação e Pesquisa da Faculdade de Ciências Econômicas da UFMG), BH: 2005.

ALMEIDA, A. L. de C.; ALMEIDA, L. H. G. A imagem organização da PUC Minas: em estudo de caso nas unidades Barreiro, Betim, Contagem, Coração Eucarístico e São Gabriel. II Congresso Abrapcorp. Anais... 2008.

ANDRADE, T. de B. A Imagem organizacional do ISAB: um estudo sob a perspectiva de seus principais públicos, 2008, 134 f. Dissertação (Programa de Pós-Graduação em Administração) - Faculdade Novos Horizontes, 2008.

ANSPACH, R. R. Shaping your bank's corporate identity. The International Journal of Bank Marketing. v.15, n.10, p.20-30, 1983.

ANTUNES, I. C. A avaliação da imagem do ensino superior privado: um estudo de caso do Instituto de Ensino Superior FUCAPI - CESF na perspectiva dos seus principais públicos, 2004, 170 f. Dissertação (Centro de Pós-Graduação e Pesquisas em Administração). Universidade Federal de Minas Gerais - UFMG, 2004.

ASHLEY, P. et al. Ética e responsabilidade social nos negócios. Rio de Janeiro: Editora Saraiva, 2003.

BARICH, H.; KOTLER, P. A framework for marketing image management. Sloan Management Review. Cambridge, v. 32, n. 2, p. 94-104, winter 1991.

BARICH, H.; SRINIVASAN, V. Prioritizing marketing image goals under resource constraints. Sloan Management Review. Summer, p. 69-76, 1993.

BARBOSA, T. G. Imagem e gerenciamento de imagem: um estudo sobre o Museu Inhotim, 2008, 139 f. Dissertação (Programa de Pós-Graduação em Administração) - Faculdade Nonos Horizontes, 2008. 
BERNSTEIN, D. Company image \& reality: a critique of corporate communications. London: Cassel Educational, 1991.

BORGES-ANDRADE, J.E. e PILATI, R. 2000. Validação de uma medida de percepção de imagens organizacionais. Revista de Administração Contemporânea, 4(1):113-134.

BRASIL. Lei ${ }^{\circ}$ 9.394, de 20 de dezembro de 1996. Dispõe sobre as diretrizes e bases da educação nacional. Brasília, DF: 1996.

CARRIERI, A. de P.; ALMEIDA, A. L. de C.; FONSECA, E. Imagem organizacional: um estudo de caso sobre a PUC Minas. Administração em Diálogo, São Paulo, no 6, 2004, pp. 23-35.

CORAZZA, G. A UNILA e a integração latino-americana. Boletim de Economia e Política Internacional. IPEA. $n^{\circ}$ 03. Jul. 2010, p.79- 88.

COSTA, J. Imagen corporativa en el siglo XXI. 2a ed. Buenos Aires: La Crujía Ediciones, 2001.

CZINKOTA, M. R. et al. Marketing: as melhores práticas: Porto Alegre: Bookman, 2001.

DESCHAMPS, J-P.; NAYAK, P. R. Produtos irresistíveis. São Paulo: Makron Books, 1996.

DOWLING, G.R. Managing Your Corporate Image. Industrial Marketing Management, 15, p.109-115, 1986.

DUTTON, J. E.; DUKERICH, J. M. Keeping an eye on the mirror: image and identity in organizational adaptation. Academy of Management Journal, v. 34, p. 517-554, 1991.

EINWILLER, S.; WILL, M. Towards an integrated approach to corporate branding - an empirical study. Corporate Communications, v. 7, n. 2, 2002.

ELSBACH, K.D.; KRAMER, R.M. Members' responses to organizational identity threats: encountering and countering the business week rankings. Administrative Science Quarterly, v.41, n.3, p. 442-476, 1996.

FERRAZ, J. J.; SOUZA, M. J. B. de; VERDINELLI, M. A. Percepção da Imagem e Satisfação em Egressos Universitários: Uma Análise Correlacional. XXXIII Encontro da ANPAD. Anais... São Paulo, 2009.

FOX, K. F. A.; KOTLER, P. Marketing estratégico para instituições educacionais. São Paulo: Atlas, 1994.

GARBETT, T. How to build a corporation's identity and project its image. Lexington, Mass.: Lexington Books, 1988. 
GEE, B. Winning the image game: a ten step masterplan for achievining power, prestige and profit. California, Page Mill Press, 1991, 147 p.

GIOIA, D. A. Organizational identity, image, and adaptive instability. Academy of Management Review, Mississippi State, jan, 2000.

GOMES, W. Transformações da política na área da comunicação de massa. São Paulo: Paulus, 2004.

GROHMANN, M. Z.; ALVARENGA, A. da S.; VENTURINI, J. C. Imagem organizacional: diferenças de percepções entre o público interno (funcionários/professores e alunos) de uma instituição de ensino superior. BASE - Revista de Administração e Contabilidade da Unisinos, 4(3):213-222, setembro/dezembro 2007.

HAIR, Jr; BLACK, W. C; BABIN, B. J; ANDERSON, R. E e TATHAM, R. L. Multivariate Data Analysis. 6a edição. Upper Saddle River, NJ: Pearson Prentice Hall, 2006.

IASBECK, L. C. A. Imagem empresarial: o lugar do cliente - a disputa pelo consumidor inverteu os valores predominantes nas hierarquias comerciais. Revista Comunicação Empresarial, São Paulo, v. 9, n. 32, p. 21-32, 1999.

IBGE. Site Institucional. População estimada de Foz do Iguaçu, 2016. Disponível em: $<\underline{\text { http://cidades.ibge.gov.br/xtras/perfil.php?lang }=\& \text { codmun }=410830 \& \text { search }=\| \text { infogr } \% \text { E1fico }}$ s:-informa\%E7\%F5es-completas $>$. Acesso em: 30 out. 2016.

KOTLER, P. Administração de marketing: análise, planejamento, implementação e controle. Tradução Ailton Bomfim Brandão. 5. ed. São Paulo: Atlas, 1998.

LINDQUIST, J. D. Meaning of image: a survey of empirical and hypothetical evidence. Journal of Retailing Amsterdam, v. 50, n. 4, p. 29-39, Winter 1974/75.

MACHADO, A. M. C. Identidade, imagem e reputação do Centro Superior de Vila Velha na perspectiva dos alunos de graduação do curso de ciências econômicas. 2001. 223 f. Dissertação (Mestrado em Administração). Universidade Federal de Minas Gerais - UFMG, 2001.

MEYER, M. L. K. A percepção da imagem de uma instituição de ensino superior, pelos alunos. 2002, 129 p. Dissertação (Centro de Pós-Graduação em Administração). Universidade Federal de Minas Gerais - UFMG, 2002.

MORAES, E. T.; LEMOS, I. W. DE; MENDONÇA, J. C. A.; GOMES, N. B. A imagem das instituições de ensino superior privadas: um estudo na região de Manhuaçu-MG. Revista Conteúdo, Capivari, v.6, n.1, jan./ago. 2014.

OLIVEIRA, G. S. S. de. Imagem Organizacional em redes sociais tecnológicas de instituições de ensino superior privadas do Estado de Minas Gerais. 2014. $113 \mathrm{f}$. Dissertação (Mestrado em Administração). Universidade FUMEC - Fundação Mineira de Educação e Cultura, 2014. 
PALACIO, A.B., MENESES, G. D.; PEREZ, P. J. P. "The configuration of the university image and its relationship with the satisfaction of students". Journal of Educational Administration, 40:486-505. 2002.

PFEFFER, J. Management as symbolic action: The creation and maintenance of organizational paradigms. In: CUMMINGS, L. L.; STAW, B. (Eds.). Research in organizational behavior. Vol. 3. Greenwich: JAI Press, 1981. p.1-52.

RAVASI, D.; VAN REKOM, J. Key issues in organizational identity and identification theory. Corporate Reputation Review, v.6, n.2, p.118-132, 2003.

REIS, M. do C. de S. Imagem Corporativa: gênese, produção e consumo. 1991. 144 f. Dissertação (Mestrado em Administração). Universidade Federal de Minas Gerais - UFMG, 1991.

REYNOLDS, T. J.; GUTMAN, J. Advertising is image management. Journal of Advertising, 1984. 24(1), 27-37.

RICOBOM, G. UNILA: A contribuição do ensino para a integração da América Latina. Revista do Centro de Educação e Letras da UNIOESTE - campus de Foz do Iguaçu, v. $12 \mathrm{n}^{\mathrm{o}} 1 \mathrm{p} .1^{\mathrm{o}}$ semestre de 2010.

A integração latino-americana e o diálogo intercultural: novas perspectivas a partir da universidade. Encontro Nacional do CONPEDI. Fortaleza: 2010.

ROESCH, S. M. A. Projetos de estágio e de pesquisa em administração: guia para estágios, trabalhos de conclusão, dissertações e estudos de caso. 3 ed. São Paulo: Atlas, 2009.

RODRIGUES, N. Por uma nova escola: o transitório e o permanente na educação. 12. ed. São Paulo: Cortez, 2000.

SCHUMACKER, R. E.; LOMAX, R. G. A beginner's guide to structural equation modeling. New Jersey: Lawrence Erlbaum Associates, 2004.

SIEGEL, S. Estatística não-paramétrica para ciências do comportamento. São Paulo, McGraw-Hill, 350 p. 1979.

TAVARES, M. C. A força da marca: como construir e manter marcas fortes. São Paulo: Harbra, 1998.

TORQUATO, G. Comunicação nas organizações: empresas privadas, instituições e setor público. São Paulo: Summus, 2015.

Tratado de Comunicação Organizacional e Política. São Paulo: Pioneira Thomson Learning, 2002.

UNIVERSIDADE FEDERAL DA INTEGRAÇÃO LATINO-AMERICANA (UNILA). Site institucional. UNILA em números, 2016. Disponível em:

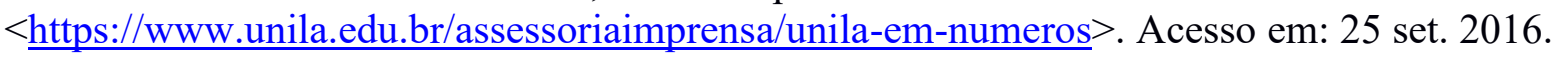


VALERIO, D. M.; PIZZINATTO, N. K. Análise da imagem organizacional de universidades por meio da matriz familiaridade-favorabilidade. Revista de Administração Mackenzie. Ano 4, n.1, p. 25-37, 2003.

VANCE, P. de S.; ÂNGELO, C. F. de. Reputação corporativa: uma revisão teórica. Revista de Gestão USP, São Paulo, v. 14, n. 4, p. 93-108, outubro/dezembro 2007.

VIANA, T. D.; COELHO, T. F.; RÊGO, A. R. A imagem da Universidade Federal do Piaú na mídia impressa e eletrônica piauiense. XIII Congresso de Ciências da Comunicação na Região Nordeste. Anais... Maceió, 2011.

VILAÇA, W. P. T. Construções identitárias em um processo de aquisição. 2003. $122 \mathrm{f}$. Dissertação (Programa de Pós-Graduação em Administração da Pontifícia Universidade Católica, PUC) Minas, Belo Horizonte, 2003.

VILLELA FILHO, R. A relação entre a comunicação integrada de marketing e a imagem institucional em uma instituição privada de ensino superior. 2015. 114 f. Dissertação (Mestrado em Administração). Universidade FUMEC - Fundação Mineira de Educação e Cultura, 2015. 